\title{
КОНЦЕПЦИИ РАЗВИТИЯ ЭТНОГРАФИЧЕСКОГО МУЗЕЯ КАЗАНСКОГО УНИВЕРСИТЕТА В XIX в.
}

\begin{abstract}
На основе архивных материалов в статье рассмотрены концепиии развития этнографического музея Казанского университета. Особое внимание уделено этапам создания этнографического собрания, специффике формирования коллекциий и особенностям реорганизации музейных структур. Авторами отмечены проблемы, с которыми столкнулся музей на этом пути, одной из них стало отсутствие заинтересованных специалистов-этнографов. Вместе с тем отмечается, что само функционирование этнографического музея в ХІХ в. способствовало накоплению большого разнопланового собрания, которое могло быть использовано для сопровождения учебного прочесса и проведения научных исследований в Казанском университете в последующие периоды.

По мнению авторов, практически за столетнюю историю своего существования этнографическое собрание Казанского университета несколько раз меняло свою «прописку», оказываясь в фондах различных структурных подразделений, и, по сути, так и не оформилось в музей. Профиль же этнографического подразделения зачастую определялся научными интересами его руководителя. Т.о. это собрание сформировалось не в результате запланированного, иеленаправленного пополнения, а спонтанно, в значительной степени за счет различных подарков университету, поэтому большую часть этнографических предметов музея составляли экспонаты из регионов, далеких от «малого отчества».
\end{abstract}

Ключевые слова: этнографический музей, концепџия, история этнографии, коллекция, музейное дело, этнография

Казанский университет в XIX в. уже в силу специфики географического положения (в столице многонационального региона на востоке Российской империи) становится одним из центров этнографического изучения народов страны и сопредельных государств Северной, Центральной и Восточной Азии. При этом в универ-

Гущина Елена Геннадьевна - к.и.н., директор Этнографического музея Казанского (Приволжского) федерального университета (420111, Казань, ул. Кремлевская, 18). Эл. почта: egguschina@mail.ru

Титова Татьяна Алексеевна - профессор, д.и.н., профессор кафедры истории Татарстана, археологии и этнографии Казанского (Приволжского) федерального университета (420111, Казань, ул. Кремлевская, 18). Эл. почта: tatiana.titova@rambler.ru

Фролова Елена Валерьевна - доцент, к.и.н., доцент кафедры истории Татарстана, археологии и этнографии Казанского (Приволжского) федерального университета (420111, Казань, ул. Кремлевская, 18). Эл. почта: elenaieup@mail.ru 
ситете так и не была создана отдельная структура, целью которой стало бы развитие этнографии как науки и учебной дисциплины: этнографическая тематика разрабатывалась на отдельных кафедрах Отделения словесных наук. С одной стороны, это объяснялось тенденциями развития самой этнографии, в то время еще не выделившейся в самостоятельную дисциплину с конкретными предметным полем, целями, задачами и методами. Быт народа, его нравы, обычаи связывались с различными сторонами человеческой деятельности, поэтому рассматривались учеными в рамках различных научных направлений (истории, статистики, географии, права). С другой стороны, в университете не было штатных специалистов, долгое время планомерно занимающихся этнографической тематикой.

Становление этнографии в Казани напрямую связано с созданием профильного музея, что было продиктовано не столько необходимостью развития нового направления, сколько стремлением сохранить уже собранные к этому времени материалы. Поскольку формирование этнографических коллекций первоначально не было направлено на решение научных или образовательных задач, новая структура должна была способствовать накоплению большого разнопланового собрания, которое можно было бы использовать как в учебном процессе, так и в научных изысканиях и культурно-просветительской деятельности. Несмотря на то что необходимость создания нового структурного подразделения была очевидна, к этой работе реально приступили только в первой четверти XX в., именно тогда в Казанском университете под руководством Б.Ф. Адлера была сформирована научная школа и создан Этнографический музей (Гущиина 2019: 183-187).

Тем не менее к обсуждению логики сбора экспонатов ученые неоднократно обращались и в XIX в., пытаясь придать музею определенную траекторию развития. Одним из первых структурных подразделений, занимавшихся формированием этнографических собраний, стал Кабинет редкостей (1815 г.), поначалу входивший в состав прописанного в Уставе университета Кабинета естественной истории. Достаточно быстро Кабинет редкостей выделился в самостоятельное структурное подразделение, но в определенной степени на его финансирование влияло то, что в Уставе он не был зафиксирован (Устав 1804: 30-32). Отметим, что музеи гуманитарного профиля в других университетах России появились позже, а их собрания состояли из коллекций живописи, скульптуры, древностей и нумизматики, поэтому Кабинет редкостей, содержащий в т.ч. и этнографические коллекции, был действительно во многом уникален.

Первые восемь лет заведующим Кабинета редкостей был ординарный профессор кафедры естественной истории и ботаники Отделения физических и математических наук К.Ф. Фукс (Загоскин 1902: 97). Его основной профессиональной деятельностью была врачебная практика, но помимо этого он занимался исследованиями в области истории, нумизматики, археологии и этнографии. Какой-либо концепции развития Кабинета редкостей у К.Ф. Фукса не было, более того, несмотря на свой интерес к этнографии татар, он не стремился к сбору и пополнению этнографических коллекций (Гущзина 2019: 24).

Следует отметить, что курировали деятельность университетских кабинетов/музеев сотрудники высокого статуса - ординарные и экстраординарные профессора. В штате музеев предполагались надзиратели (чуть позже эту должность стали называть «хранитель»; как правило, надзирателями/хранителями были профессора, адъюнкты или сотрудники-кандидаты, оставленные при университете для подготовки 
к профессорскому званию). Должностные обязанности хранителей были достаточно обширны: они следили за порядком, отвечали за сохранность материалов, вели учетную документацию и курировали работу студентов и преподавателей с коллекциями. По факту же в кабинете/музее, особенно если он не был «прописан» в Уставе и на него не выделялись штатные должности и бюджетные деньги, был только заведующий, а хранитель зачастую занимался сразу несколькими музеями. Сам факт, что руководство кабинетами доверялось профессорам, свидетельствует о том, что коллекции рассматривались как важная часть учебного процесса, как база для научных изысканий (Бурлыкина 1996: 17). Такая практика сохранялась в Казанском университете на протяжении XIX-XX вв.

Первые этнографические предметы в собрании Кабинета редкостей - по большей части костюмы народов Сибири - были переданы в дар студентами и сотрудниками университета и подшефных ему образовательных организаций (Гущина 2019: 34). А первая крупная коллекция состояла из материалов, собранных И.М. Симоновым на островах Океании во время Первой русской антарктической экспедиции (1819-1821 гг.). Но систематическое пополнение Кабинета редкостей тематическими этнографическими коллекциями и целенаправленная деятельность по формированию качественного музейного собрания связаны с развитием в Казанском университете востоковедения и именем О.М. Ковалевского, в период работы в Казани (1824-1862 гг.) занимавшегося восточными языками (тюркскими, арабским, фарси и монгольским) (Валеев 2002: 5-7). Отметим, что после ухода К.Ф. Фукса (в 1823 г.) за восемь лет сменилось несколько заведующих кабинетом.

Для изучения народов Востока университет организовывал экспедиции в места их проживания, и в результате был собран огромный материал по филологии, географии и страноведению. Многочисленные предметы быта и культа пополнили коллекции музеев университета (Столярова и др. 2015: 38). В 1828 г. О.М. Ковалевский вместе со студентом А.В. Поповым был командирован на четыре года в Иркутск для изучения монгольского языка, в этот период он посетил Забайкалье, Монголию и Китай. Ученый общался с носителями языка, а благодаря личному знакомству с бурятскими ламами и установившимся дружественным отношениям с представителями других этносов он получил возможность собрать очень редкие и ценные экспонаты. В университет О.М. Ковалевский привез большое собрание рукописей и книг, ценную коллекцию китайских, монгольских и бурятских бытовых и культовых вещей (Отчет 1840: 36-37).

По возвращению в Казань О.М. Ковалевский становится заведующим Кабинетом редкостей, он совмещает эту деятельность с преподавательской работой. Одной из причин прихода О.М. Ковалевского на эту должность, как нам кажется, явилось его желание заняться исследованием собранных в экспедиции полевых материалов. Предназначение Кабинета редкостей ученый видел в т.ч. в сопровождении учебного процесса и научных исследований по направлению «Востоковедение». Нами не обнаружено каких-либо документов, в которых О.М. Ковалевский прямо излагал бы свои идеи по развитию возглавляемого им структурного подразделения. Но анализ архивных материалов позволяет говорить о том, что ученый стремился придать кабинету характер музея культуры народов Востока, что прежде всего отвечало научным интересам самого заведующего. Помимо экспедиционных материалов, привезенных для музея О.М. Ковалевским, этнографическая коллекция при нем 
пополнялась передаваемыми в дар или целенаправленно приобретаемыми на выделенные университетом средства предметами, отражающими традиционную бытовую и религиозную культуру народов Забайкалья. Восточное собрание Кабинета редкостей продолжало планомерно расширяться в 40-50-е годы XIX в. за счет передаваемых безвозмездно буддийскими священнослужителями, предположительно лично знакомыми с О. М. Ковалевским, вещей, а также за счет экспедиционных материалов российских ученых и даров различных официальных лиц. При этом нельзя утверждать, что пополнение Кабинета редкостей новыми предметами происходило только в рамках Восточного собрания. В это время в музее появились коллекции по народам Америки (от Д.Ф. Зарембо, В.Ф. Берви), а также «непрофильные» экспонаты - окаменелости, пушечные ядра и т.п. К началу 50-х годов XIX в. в его фондах насчитывалось уже 553 предмета на сумму 1978 рублей (Записки 1843: 52).

С середины 1850-х годов, после отъезда О.М. Ковалевского в Санкт-Петербург, начавшаяся планомерная работа по комплектованию музея восточными коллекциями была остановлена. Кабинет редкостей, оставшийся без заведующего, оказался в состоянии стагнации: пополнения экспонатами не происходило, решение вопросов определения положения подразделения в структуре университета и назначения нового руководителя затягивалось. Только в 1856-1860 гг. в музее сменилось три заведующих (В.И. Григорович, С.В. Ешевский, Н.А. Попов). Вместе с тем этот период стал временем поиска пути дальнейшего развития. Определение траектории комплектования фондов новыми коллекциями, разработка новых целей и задач связаны с именами историков С.В. Ешевского и пришедшего в 1860 г. на должность заведующего Кабинетом редкостей Н.А. Фирсова.

Несмотря на то что С.В. Ешевский лишь около года проработал руководителем подразделения, именно ему принадлежит идея его реорганизации. По инициативе С.В. Ешевского Кабинет редкостей был переименован в Музей местных древностей и этнографии. Изменилось не просто название, изменилась стратегия развития и появилась определенная концепция. Согласно плану С.В. Ешевского, в новом музее должно было быть сформировано крупное собрание предметов, прежде всего связанных с археологией. Это соответствовало задачам университета и способствовало развитию исторических дисциплин, в т.ч. этнографии (Отчет 1858: 19). Уже название нового подразделения очерчивало сферу деятельности ученых Императорского Казанского университета и в целом Поволжья - изучение родного края, развитие краеведения и археологических изысканий; о комплексных этнографических исследованиях народов Поволжья (что в источниках часто обозначается как «современность») речь не шла.

Для реализации своей идеи С.В. Ешевский обратился к заведующим учебными заведениями Казанского учебного округа с просьбой передавать в университет сведения о «местных древностях» (Отчет 1858: 22). Анализ текста обращения показывает, что под «местными древностями» имелись в виду прежде всего памятники археологии - могильники, курганы, развалины зданий и т.п. С.В. Ешевский понимал, что могут возникнуть сложности в отборе, поэтому рекомендовал использовать в качестве методического руководства «записку о собирании Русских древностей, 
изданную археологическим обществом» ${ }^{1}$. И уже в 1858 г. в Музей местных древностей и этнографии поступило сразу несколько разрозненных археологических предметов, найденных и собранных на территории Среднего Поволжья. В основном это были экспонаты, относящиеся к периоду Волжской Булгарии (ГА РТ. Д. 2186. Л. 9).

После отъезда С.В. Ешевского в Москву пополнение фондов предметами «древностей» уже не носило массового характера, прежде всего из-за отсутствия заинтересованного в развитии музея руководителя. Сам музей превратился в хранилище этнографических (восточноазиатские, сибирские, поволжские, океанийские, американские коллекции) и по большей части археологических («булгарские древности», вещи, относящиеся к каменному и бронзовому векам) предметов, которые не были четко дифференцированы по темам.

В 1860 г. музей возглавил Н.А. Фирсов, который и оставался его руководителем на протяжении более чем 30 лет. Это был период перемен, обусловленных принятием нового Университетского устава 1863 г. и необходимостью устранения расхождений между прописанными в нем и реально существующими музеями. В судьбе коллекций (в их слиянии или разделении) значительную роль играл фактор наличия/отсутствия заведующего и хранителя, способных обеспечивать нормальное функционирование подразделения. В результате в 1885 г. было принято решение о создании Музея отечествоведения (по сути, преемника Музея местных древностей и этнографии с его краеведческим профилем), куда были переданы этнографические коллекции. Н.А. Фирсов ставил задачу пополнения уже существующего собрания историческими, археологическими и этнографическими экспонатами, раскрывающими традиционную культуру народов северо-востока России, но сам не предпринимал никаких реальных шагов в этом направлении, а деньги, выделяемые университетом для музея, шли на создание исторической библиотеки (Гущзина 2019: 63), и лишь изредка приобретались отдельные предметы. При этом в дар музею передавалось значительно больше предметов из различных регионов мира. Получалось, что большая часть собрания по-прежнему оставалась экзотической, а коллекции, характеризующие культуру и быт народов Поволжья, были небольшими, фрагментарными и, как отмечалось выше, в основном археологическими. Таким образом, идея музея как презентационного пространства истории народов северо-востока Российской империи не была реализована.

В этот период Общество археологии, истории и этнографии при Казанском университете начинает развивать новую комплексную дисциплину - финноугроведение. Один из представителей нового направления историк И.Н. Смирнов предпринимает попытку скорректировать деятельность Музея отечествоведения, он обсуждает необходимость его реорганизации с Н.А. Фирсовым. По мнению И.Н. Смирнова, «провинциальный музей» с ограниченными средствами априори не может претендовать на отражение истории и культуры всех народов России, однако он может представлять «малое отечество» - Поволжье и прежде всего финно-угорские народы, которые и должны стать объектом его исследования. Для того чтобы сформировать в музее качественный презентационный материал, С.И. Смирнов предлагал собирать коллекции непосредственно в экспедициях. Он справедливо указывал на то, что уже

\footnotetext{
${ }^{1}$ По всей видимости, имеется в виду «Записка для обозрения русских древностей», вышедшая в качестве приложения в первом сборнике «Записок Отделения русской и славянской археологии Русского археологического общества». По своей сути «Записка...» представляла собой программу собирания памятников старины.
} 
хранящиеся в фондах предметы и коллекции, имеющие отношение к этнографии народов Поволжья, разрозненны и дают «весьма неопределенное представление о том, как живут местные финские народности». Кроме того, ученый отмечал, что большая часть находящихся в музее предметов - это элементы костюма, а бытовой и культовой утвари практически нет (ГА РТ. Д. 1395. Л. 1-2).

И.Н. Смирнов подчеркивал важность научного комплектования музея археологическими и этнографическими коллекциями по народам Волго-Уралья, рассматривая этнографические коллекции по «современной культуре» как способ дешифровки предметов, собранных во время раскопок: «Без ясных представлений о современной культуре финских народностей края невозможны основательные археологические исследования; без коллекций, рисующих современный быт местных финнов, неясны коллекции, доставленные путем раскопок» (ГА РТ. Д. 1395. Л. 1-2).

Н.А. Фирсов поддерживал основную идею И.Н. Смирнова о создании комплексного музея по этнографии народов Поволжья и отмечал, что для это нужно использовать систему целенаправленного научного комплектования фондов, в отличие от применявшейся ранее, когда основная часть предметов передавалась в дар или покупалась «по случаю». Предполагалось, что ежегодно будут выделяться средства на организацию научных экспедиций. Этот проект развития Музея отечествоведения поддержала администрация университета, и в 1888-1895 гг. под руководством И.Н. Смирнова был организован ряд экспедиций в места компактного проживания финно-угорских народов на территории Среднего Поволжья (в Казанскую, Нижегородскую, Вятскую, Пермскую, Уфимскую губернии). По результатам исследований И.Н. Смирнов выступал с докладами на собраниях историко-филологического факультета и Общества археологии, истории и этнографии. Позже, обобщив материалы поездок, он опубликовал в «Известиях Общества археологии, истории и этнографии при Императорском Казанском университете» фундаментальные историко-этнографические очерки «Черемисы», «Вотяки» и «Мордва».

Однако нельзя утверждать, что задуманная Н.А. Фирсовым и И.Н. Смирновым концепция развития Музея отечествоведения была реализована полностью. Безусловно, в результате экспедиционной деятельности в эти годы фонды музея пополнились предметами и ценными фотографиями по этнографии финно-угорских (в основном марийцев, удмуртов) и тюркских (чуваши, кряшены) народов Поволжья. Была создана тематическая экспозиция, в основу которой был положен сравнительно-сопоставительный принцип, что позволяло И.Н. Смирнову делать выводы о генезисе, взаимовлиянии и типологии элементов традиционной культуры народов Волго-Уральского региона (Смирнов 1892: 443). Но экспозиция содержала информацию не по всем народам края, а представленные коллекции отличались размерами и не позволяли составить полную картину региона.

В 1896 г. должность заведующего Музеем отечествоведения занял историк Д.А. Корсаков. Он, как и его предшественники, продолжил комплектовать фонды предметами по «местному отечеству», но пополнение шло в меньших масштабах, чем ранее, и в основном приобретались образцы русского декоративно-прикладного искусства (головные уборы, парчовые сарафаны и холодники, бытовая утварь). Вместе с тем в дар музею по-прежнему передавались интересные собрания по народам Неевропейской России и мира (и таких предметов поступало достаточно много). Так, в это период Н.Ф. Катанов передал в музей коллекцию по хакасскому шаманизму. 
Кроме того, на состояние Музея отечествоведения и его экспозиции большое негативное влияние оказывало отсутствие постоянного, подходящего по размеру, оборудованного помещения. Музей располагался на антресольном этаже западного крыла главного университетского здания над учебными аудиториями и делил помещения с начавшим реально функционировать и пополняться коллекциями Музеем изящных искусств и древностей. Только в 1895 г. для Музея отечествоведения были выделены две дополнительные комнаты, что должно было бы разгрузить пространство, однако в них для удобства работы преподавателей и ученых были перенесены библиотека и лекторий (Сведения 1896: 45), кроме того, здесь же в упакованном виде хранились коллекции Общества археологии, истории и этнографии, т.к. у него не было своего помещения. Из-за нехватки площадей экспонировалась только часть собрания. Большинство предметов просто были сложены в коробки и сундуки, не предназначенные для нормального хранения культурных ценностей. Коллекции не были систематизированы, большая их часть была недоступна (не только для работы, но и просто для ознакомления), не велась планомерная работа с фондами (Протоколы 1899: 38).

Более того, в процессе развития этнографического отдела Музея отечествоведения сказывалась и нехватка специалистов. Для организации научного описания и разбора предметов нужен был руководитель, занимающийся этнографической тематикой, владевший вопросами музееведения. Заведующие Музеем отечествоведения Н.А. Фирсов и Д.А. Корсаков, хоть и обладали энциклопедическими знаниями, но все же были классическими историками. Этнографию они воспринимали как вспомогательную дисциплину, которая полезна для подготовки учителей истории и географии. Занимаясь историей России, они планировали музей, в котором ведущее место занимали бы экспозиции по русскому населению, тогда как коллекции по «инородцам» служили бы своеобразной иллюстрацией перехода от более «примитивной» культуры к более «цивилизованной». Еще И.Н. Смирнов в свое время, обосновывая важность преподавания этнографии и географии на историко-филологическом факультете, отмечал, что практическая цель такого преподавания - воспитание учительских кадров, которые в интересах государства способствовали бы «ассимиляции инородцев с господствующей народностью» (Протоколы 1899: 38).

Не имея необходимых навыков работы с этнографическими коллекциями (даже просто музееведческих навыков), ни Н.А. Фирсов, ни Д.А. Корсаков не могли реализовать потенциал собраний Музея отечествоведения - да и предметы по народам мира и неевропейской части России составляли значительную его часть. Возникли сложности с научной систематизацией, описанием и экспонированием многих этнографических предметов. Вот почему большая часть закупок этого времени была связана с пополнением библиотеки и «исторических» собраний различными предметами: портретами, грамотами, фотографиями, имеющими отношение к императорской фамилии или представителям местной администрации. Из этнографических собраний только финно-угорское более-менее планомерно формировалось и развивалось. По сути, хранящиеся в музее коллекции могли наглядно представлять культуру народов не только «малого отечества», но и гораздо большего числа регионов России и мира, но они не были задействованы ни в учебном, ни в научном процессах, не представляли интереса ни для студентов, ни для преподавателей. Д.А. Корсаков планировал организовать в музее особый отдел с пособиями по истории и географии (учебники, карты, атласы, картины, приборы), с которыми должны были знакомиться студенты 
историко-филологического факультета, но использование этнографических коллекций им вообще не рассматривалось. Сложность и разнородность музейного собрания, отсутствие каталогов, научного описания и планомерной работы с фондами - все это требовало принятия каких-то решений. Д.А. Корсаков предложил начать с систематизации собрания портретов русских деятелей и запланировал создание коллекций по географии (виды местностей, городов, типы населения) (Протоколы 1899: 139).

$* * *$

Таким образом, практически за столетнюю историю своего существования этнографическое собрание Казанского университета несколько раз меняло свою «прописку», оказываясь в фондах различных структурных подразделений, и, по сути, так и не оформилось в музей. Это собрание сформировалось не в результате запланированного, целенаправленного пополнения, а спонтанно, в большей степени за счет различных подарков университету. Профиль же этнографического подразделения зачастую определялся научными интересами его руководителя. Так, Кабинет редкостей в 30-х годах XIX в. приобрел характер этнографического музея по культуре народов Востока, что было связано с деятельностью О.М. Ковалевского, занимавшегося востоковедением; в эти годы, благодаря экспедициям ученых восточного разряда, Кабинет редкостей пополнился большим числом материалов по народам Азии. Именно в этот период этнографические коллекции стали восприниматься как научный источник для изучения традиционной материальной и духовной культуры. Планомерное развитие кабинета в рамках востоковедения было прервано переводом восточного разряда университета в Санкт-Петербург в середине XIX в.

Отсутствие заинтересованного и разбирающегося в материале руководителя сказалось на дальнейшем функционировании музея и привело к отрыву музейного собрания от исследовательских практик. Позднее были предприняты попытки сместить вектор развития в сторону краеведения и отечествоведения. В большей степени эти планы удалось реализовать в 1880-1890-е годы благодаря целенаправленной работе Н.И. Смирнова. Тем не менее проект Музея истории, археологии и этнографии малого отечества не был полностью воплощен. Этнографическое собрание по народам Волго-Уралья было неоднородным, только финно-угорские коллекции можно охарактеризовать как наиболее полные, но и они не отвечали задаче комплексного отражения какого-либо народа, а показывали материальную культуру отдельных локальных групп. При этом большую часть этнографических предметов музея составляли экспонаты из регионов, далеких от «малого отчества». Смена руководителей, их недостаточная квалификация в работе с этнографическими предметами, как и отсутствие у заведующих музееведческих навыков, не позволили реализовать в полной мере потенциал коллекций и тормозили развитие музея.

\section{Источники и материалы}

ГА РТ - Государственный архив Республики Татарстан. Ф. 977. Оп. Истфилфак.

Загоскин 1902 - Загоскин Н.П. История Императорского Казанского университета за первые 100 лет его существования. Казань: Типо-литография Императорского Казанского университета, 1902. Т. 3.

Записки 1843 - Записки о кабинетах и других заведениях при Императорском Казанском университете, со времени учреждения каждого из них по 1 мая 1843 г. Казань: Универси- 
тетская типография, 1843.

Отчет 1840 -Отчет о состоянии Императорского Казанского университета за 1839-1840 академический год. Казань: Тип. Казанского ун-та, 1840.

Отчет 1858 - Отчет о состоянии Императорского Казанского университета за 1857-1858 академический год. Казань: Тип. Казанского ун-та, 1858.

Протоколы 1899 - Протоколы заседаний Совета Императорского Казанского университета за 1898 год // Ученые записки Императорского Казанского университета. Казань: Типография университета, 1899. № 9.

Сведения 1896 - Сведения о состоянии Казанского университета за 1894 г. и первое полугодие 1895 г. // Ученые записки Императорского Казанского университета. Казань: Типография университета, 1896. № 1.

Смирнов 1892 - Смирнов И.Н. Музей Отечествоведения // Известия Общества археологии, истории и этнографии при Казанском университете. 1892. Т. Х. Вып. 4. С. 442-446.

Устав 1804 - Устав Императорского Казанского университета. [Б.м.: Б. и.], 1804.

\section{Научная литература}

Бурлькина М.И. Университетские музеи дореволюционной России (XVIII - первая четверть XX вв.). Сыктывкар: Сыктывкарский гос. ун-тет, 1996.

Валеев Р.М. Осип Михайлович Ковалевский, 1801-1878. Казань: Изд-во Казанского ун-та, 2002.

Гущцина Е.Г. Этнографическое собрание Императорского Казанского университета: история формирования и развития // Известия общества археологии, истории и этнографии при Казанского университете. Казань, 2019. Т. 39. № 1-2.

Столярова Г.Р., Гущина Е.Г., Титова Т.А. Восточные коллекции Кабинета редкостей Казанского Императорского университета // Вестник КАЗГУКИ. 2015. № 4. Ч. 2. С. 37-40.

Gushchina, Elena G., Titova, Tatiana A., and Frolova, Elena $V^{*}$

\section{Scientific concepts of the Ethnographic Museum of Kazan University in the $19^{\text {th }}$ century}

DOI: $10.33876 / 2311-0546 / 2020-52-4 / 115-124$

The article discusses the developmental concept of the Ethnographic museum of Kazan University in the context of development of ethnographic knowledge. Particular attention is paid to the stages of formation of the ethnographic collection, the specifics of formation of collections and aspects of reorganization of museum structures. The authors highlighted the problems that the museum collection faced in the period under review: the lack of interested ethnographers and planned museum work. However, it was concluded that functioning of the Ethnographic museum in the XIX century contributed to accumulation of a large diverse collection, which provided support for the educational process and scientific research at Kazan University later.

Over almost a hundred-year history the ethnographic collection of Kazan University changed its affiliation several times, ending up in funds of various structural divisions, and, in fact, never became a museum. The profile of an ethnographic unit was often defined by the scientific interests of its head. Thus, this collection was formed not as a result of a planned, purposeful replenishment, but rather spontaneously, largely due to various gifts to the university, and therefore, most of the museum's ethnographic exhibits came from regions that were far from the "small motherland".

Key words: ethnographic museum, concept, history of ethnography, collection, museum work, ethnography 
* Gushchina, Elena G. - Candidate of Historical Sciences, Director of the Ethnographic Museum of Kazan Federal University (Kazan, Russia). E-mail: egguschina@mail.ru

Titova, Tatiana A. - Professor, Doctor of Historical Sciences, Professor of the Department of History of Tatarstan, Archeology and Ethnography Kazan Federal University (Kazan, Russia). E-mail: tatiana.titova@rambler.ru

Frolova, Elena V. - Candidate of Historical Sciences, Associate Professor of the Department of History of Tatarstan, Archeology and Ethnography of Kazan Federal University (Kazan, Russia). E-mail: elenaieup@mail.ru

\section{References}

Burlykina, M.I. 1996. Universitetskie muzei dorevoliutsionnoi Rossii (XVIII - pervaia chetvert' XX vv.) [University Museums of Pre-Revolutionary Russia $18^{\text {th }}-$ the First Quarter of the $20^{\text {th }}$ Centuries)]. Syktyvkar: Syktyvkarskii gosudarstvennyi universitet.

Valeev, R.M. 2002. Osip Mikhailovich Kovalevskii, 1801-1878 [Osip Mikhailovich Kovalevskiy, 1801-1878]. Kazan: Izdatel'stvo Kazanskogo universiteta.

Gushchina, E.G. 2019. Etnograficheskoe sobranie Imperatorskogo Kazanskogo universiteta: istoriia formirovaniia i razvitiia [Ethnographic Collection of the Imperial Kazan University: History of Formation and Development]. Izvestiia obshchestva arkheologii, istorii $i$ etnografii pri Kazanskom universitete 39 (1-2).

Stoliarova, G.R., E.G. Gushchina, and T.A. Titova. 2015. Vostochnye kollektsii Kabineta redkostei Kazanskogo Imperatorskogo universiteta [Eastern Collections of the Cabinet of Rarities of Kazan Imperial University]. Vestnik KAZGUKI 4 (2): 37-40. 